\title{
TpTe and TpTe/QT: novel markers to predict sudden cardiac death in ESRD?
}

TpTe eTpTe/QT: novos marcadores para prever morte súbita cardíaca na DRT?

\section{Authors}

Basil M. Saour ${ }^{1,2,3}$

Jeffrey H. Wang ${ }^{4}$

Michael P. Lavelle ${ }^{1}$

Roy O. Mathew ${ }^{5}$

Mandeep S. Sidhu ${ }^{2,3}$

William E. Boden ${ }^{2,3}$

Joseph D. Sacco ${ }^{2,3}$

Eric J. Costanzo ${ }^{6}$

Mohammad A. Hossain ${ }^{6}$

Tuhsar Vachharanji

Anas Alrefaee ${ }^{6}$

Arif Asif ${ }^{6}$

${ }^{1}$ Albany Medical College, Albany, NY, USA.

${ }^{2}$ Stratton VA Medical Center, Department of Medicine, Division of Cardiology, Albany, NY, USA.

${ }^{3}$ Albany Medical College,

Department of Medicine, Division of Cardiology, Albany, NY, USA.

${ }^{4}$ Hennepin County Medical

Center, Department of Medicine,

Division of Nephrology,

Minneapolis, MN, USA.

${ }^{5}$ WJB Dorn VA Medical Center, Department of Medicine, Division of Nephrology, Columbia, SC,

USA.

${ }^{6}$ Jersey Shore University Medical College, Seton Hall HackensackMeridian School of Medicine,

Department of Medicine, Neptune, New Jersey, USA.

${ }^{7}$ Salisbury VA Health Care System, Department of Nephrology, North Carolina, USA.

Submitted on: $12 / 08 / 2017$ Approved on: 28/05/2018.

\section{Correspondence to:}

Arif Asif.

E-mail: arif.asif@hackensackmeridian. org

DOI: 10.1590/2175-8239-JBN-2017-0021

\section{Abstract}

Introduction: Reliable markers to predict sudden cardiac death (SCD) in patients with end stage renal disease (ESRD) remain elusive, but echocardiogram (ECG) parameters may help stratify patients. Given their roles as markers for myocardial dispersion especially in high risk populations such as those with Brugada syndrome, we hypothesized that the Tpeak to Tend (TpTe) interval and $\mathrm{TpTe} / \mathrm{QT}$ are independent risk factors for SCD in ESRD. Methods: Retrospective chart review was conducted on a cohort of patients with ESRD starting hemodialysis. Patients were US veterans who utilized the Veterans Affairs medical centers for health care. Average age of all participants was 66 years and the majority were males, consistent with a US veteran population. ECGs that were performed within 18 months of dialysis initiation were manually evaluated for $\mathrm{TpTe}$ and $\mathrm{TpTe} / \mathrm{QT}$. The primary outcomes were SCD and all-cause mortality, and these were assessed up to 5 years following dialysis initiation. Results: After exclusion criteria, 205 patients were identified, of whom 94 had a prolonged $\mathrm{TpTe}$, and 61 had a prolonged $\mathrm{TpTe} /$ QT interval (not mutually exclusive). Overall mortality was $70.2 \%$ at 5 years and SCD was $15.2 \%$. No significant difference was observed in the primary outcomes when examining TpTe (SCD: prolonged $16.0 \%$ vs. normal $14.4 \%$, $p=0.73$; all-cause mortality: prolonged $55.3 \%$ vs. normal $47.7 \%, p=0.43$ ). Likewise, no significant difference was found for TpTe/QT (SCD: prolonged $15.4 \%$ vs. normal $15.0 \%, p=0.51$; allcause mortality: prolonged $80.7 \%$ vs. normal $66.7 \%, p=0.39)$. Conclusions: In ESRD patients on hemodialysis, pro-

\section{Resumo}

Introdução: Marcadores confiáveis para predizer morte súbita cardíaca (MSC) em pacientes com doença renal terminal (DRT) permanecem elusivos, mas os parâmetros do ecocardiograma (ECG) podem ajudar a estratificar os pacientes. Devido a seus papéis como marcadores para a dispersão miocárdi$\mathrm{ca}$, especialmente em populações de alto risco, como aquelas com síndrome de Brugada, nós hipotetizamos que o intervalo pico da onda $\mathrm{T}$ ao final da onda $\mathrm{T}$ (TpTe) e TpTe/QT são fatores de risco independentes para MSC na DRT. Métodos: Revisão retrospectiva do prontuário foi realizada em uma coorte de pacientes com DRT iniciando a hemodiálise. Os pacientes eram veteranos de guerra americanos que utilizavam os centros médicos do Veterans Affairs para atendimento médico. A idade média de todos os participantes foi de 66 anos e a maioria era do sexo masculino, consistente com uma população veterana dos EUA. ECGs que foram realizados dentro de 18 meses após o início da diálise, e foram avaliados manualmente para TpTe e $\mathrm{TpTe} /$ QT. Os desfechos primários foram MSC e mortalidade por todas as causas, e estes foram avaliados até 5 anos após o início da diálise. Resultados: Após o critério de exclusão, foram identificados 205 pacientes, dos quais $94 \mathrm{com}$ $\mathrm{TpTe}$ prolongado e $61 \mathrm{com}$ intervalo $\mathrm{TpTe} /$ QT prolongado (não mutuamente exclusivo). A mortalidade geral foi de $70,2 \%$ em 5 anos e a MSC foi de 15,2\%. Nenhuma diferença significativa foi observada nos desfechos primários ao se avaliar o TpTe (MSC: prolongado $16,0 \%$ versus normal $14,4 \%, p=0,73$; mortalidade por todas as causas: prolongado $55,3 \%$ vs. normal $47,7 \%, p=0,43)$. Da mesma forma, nenhuma diferença significativa foi encontrada para TpTe/QT (MSC: prolongado $15,4 \%$ vs. normal $15,0 \%, p=0,51$; mortalidade por todas as causas: prolongado $80,7 \%$ vs. normal $66,7 \%, p=0,39)$. Conclusões: Em 
longed $\mathrm{TpTe}$ or $\mathrm{TpTe} / \mathrm{QT}$ was not associated with a significant increase in SCD or all-cause mortality.

Keywords: Death, Sudden; Kidney Failure, Chronic; TpTe. pacientes com insuficiência renal terminal em hemodiálise, $\mathrm{TpTe}$ ou $\mathrm{TpTe} / \mathrm{QT}$ prolongados não foram associados a um aumento significativo da morte súbita ou mortalidade por todas as causas.

Palavras-chave: Morte Súbita; Falência Renal Crônica; TpTe.

\section{INTRODUCTION}

Sudden cardiac death (SCD) is the leading cause of mortality in patients with end stage renal disease (ESRD) treated with hemodialysis, accounting for $26.9 \%$ of all deaths in this population. ${ }^{1}$ In the United States, the incidence of SCD in the general population is $53 / 100,000$; the primary identifiable risk factors are reduced systolic function with a depressed left ventricular ejection fraction or a history of prior sudden cardiac arrest. ${ }^{2-4}$ These characteristics do not have the same predictive ability in ESRD. Bleyer et al. reported that $75 \%$ of dialysis patients who died of SCD have a left ventricular ejection fraction $>35 \% .^{5}$ To date, there is no reliable risk stratification marker to identify dialysis patients at high arrhythmic risk for sudden cardiac arrest. ${ }^{5-7}$

Current efforts aimed at identifying SCD risk stratification markers have focused on ECG data. In the general population, ECG findings with validated evidence to support primary prevention of SCD with an implantable cardioverter-defibrillator (ICD) are those linked to an underlying cardiomyopathy or impaired ion channel function, such as Brugada pattern, Arrhythmogenic Right Ventricular Dysplasia with an Epsilon wave, or prolonged QT. ${ }^{8}$ Electrolyte and fluid shifts during hemodialysis combined with the increased prevalence of myofibrosis in this population, is thought to predispose individuals to ventricular arrhythmias, which may manifest as derangements in ECG parameters. ${ }^{6,9}$ Recent literature suggests that various ECG changes, such as prolonged PR, QRS, or QTc intervals, may be independent risk predictors for cardiovascular $(\mathrm{CV})$ death in patients with chronic kidney disease. ${ }^{10-12}$

Tpeak-Tend (TpTe) and TpTe/QT intervals are ECG markers of arrhythmogenesis, which reflect the degree of heterogeneity of repolarization in the myocardium. ${ }^{13}$ In the general population, a prolonged TpTe is associated with a 2 -fold higher risk of SCD. ${ }^{14}$ Furthermore, prolonged TpTe or prolonged TpTe/QT intervals have demonstrated potential utility for prediction of SCD in patients with hypertrophic obstructive cardiomyopathy, long QT syndrome, and those undergoing percutaneous coronary intervention. ${ }^{15,16}$ Although hemodialysis has been shown to prolong the TpTe interval, no study have examined the predictive ability of a baseline TpTe interval in patients with ESRD. ${ }^{17}$ We hypothesized that TpTe and TpTe/QT are independent risk factors for SCD in ESRD. The aim of this study was to assess the prognostic value of TpTe and TpTe/QT for SCD in ESRD patients, independent of the mechanism for prolongation of the TpTe interval.

\section{Methods}

\section{STUDY POPULATION}

This retrospective cohort study included veterans with ESRD from the 5 upstate New York Veterans Affairs medical centers. All data was obtained from clinical information that was already collected and stored within the Veterans Affairs corporate data warehouse, no patients were formally interviewed or examined as the study was retrospective in nature. All consecutive patients who initiated outpatient in-center hemodialysis between January 1, 2000, and December 31, 2007, and dialyzed for at least 90 days were included.

Although it is routine that an ECG be conducted prior to the initiation of hemodialysis, this was unfortunately not always done in our patient sample. Furthermore, given the dynamic nature of ECGs in patients, especially in those with advanced renal disease, the first ECG that was examined was often not interpretable for evaluation of the TpTe segment. Thus, we defined the "baseline" ECG as the first suitable ECG after dialysis initiation.

Inclusion criteria were age $>18$ and having an ECG within 18 months of dialysis initiation. Exclusion criteria were patients not dialyzed within the study time-frame, missing dialysis initiation date, unsuitable ECG (not in sinus rhythm, poor technical quality, left bundle branch block, QRS > 120ms), pre-existing ICD or permanent pacemaker (PPM), pregnancy, renal transplantation, or treated with peritoneal or home hemodialysis. 
The Albay Stratton VA Medical Center Institutional Review board and Research and Development Committee approved this study under expedited review.

\section{ELECTROCARDIOGRAPHIC ANALYSIS}

ECGs were analyzed at $25 \mathrm{~mm} / \mathrm{s}$ paper speed and 10 $\mathrm{mm} / \mathrm{mV}$ amplitude. All measurements were performed by a board-certified cardiologist. Baseline parameters from the ECG included manual measurements of the TpTe segment and QT interval. TpTe was calculated from the difference of the QT interval and the QRS complex to Tpeak interval (Figure 1). The QT interval was measured from the beginning of the QRS complex to the end of the T wave. The corrected QT interval (QTc) was obtained using Bazett's formula $(\mathrm{QTc}=\mathrm{QT} / \sqrt{\mathrm{R} R}$ interval $)$. A prolonged TpTe segment was defined as $>85 \mathrm{~ms}$, while a prolonged TpTe/QT segment was defined as $>0.25 . .^{14}$ The axis, presence of left ventricular hypertrophy (via Sokolow-Lyon criteria), right bundle branch block, non-specific intraventricular conduction delay, and left anterior or posterior fascicular block were recorded. QRS duration, heart rate, and PR interval were obtained from the ECG computer measurement. In accordance with previous studies, lead V5 was used for the measurements. ${ }^{14-16}$ If V5 was not interpretable, V4, then V6 was used.

\section{POWER ANALYSIS}

There is no previous report in the literature on the rate of SCD in dialysis patients with a normal TpTe interval to guide the sample size calculation. Although we acknowledge that ESRD patients are a different substrate than the general population, using data from the general population we estimated that a dialysis patient with a normal TpTe has a $19 \%$ probability of dying from SCD 5 years after dialysis initiation. ${ }^{14}$ We hypothesized that having a prolonged $\mathrm{TpTe}$ interval increases the probability of SCD at 5 years by 2.2 -fold. Thus, if we had 2 controls per case, we needed 135 patients ( 45 with prolonged $\mathrm{TpTe}$ and 90 with non-prolonged $\mathrm{TpTe}$ ) to be able to reject the null hypothesis with power of 0.8 . The type 1 error probability associated with this test of null hypothesis is 0.05 . The sample size calculation was performed with the Power and Sample Size Program 3.0 (Vanderbilt University, Nashville, TN).

\section{ADJUDICATION OF SUDDEN CARDIAC DEATH}

Mortality status and cause of death were obtained from the Centers for Medicare and Medicaid Services 2746 death notification form through a data request to the United States Renal Data System registry. Death from cardiac arrhythmia or cardiac arrest, cause unknown, was considered meeting criteria for SCD. Outcomes were assessed up to a maximum of 5 years following initiation of hemodialysis therapy.

\section{DATA ANALYSIS}

Statistical analyses were conducted using SigmaPlot 12 (San Jose, CA). Baseline characteristics between subjects with a prolonged $\mathrm{TpTe}$ (and $\mathrm{TpTe} / \mathrm{QT}$ ) were compared using the two-tailed unpaired Student's t-test for continuous variables and the Pearson $\chi^{2}$ test for categorical data. Time-to-event analysis was performed using the Kaplan-Meier method with log-rank test. Statistical significance was defined as $p<0.05$.

\section{Results}

\section{Patient SELECTION}

The initial search of the VA database yielded $402 \mathrm{pa}$ tients. After exclusion criteria were applied, 205 subjects remained. The major reasons for exclusion were the absence of an acceptable ECG within 18 months after starting dialysis $(\mathrm{N}=59)$, use of peritoneal dialysis $(\mathrm{N}=36)$, and technically unsuitable ECG $(\mathrm{N}=37)$ (Figure 2). Of the 205 that remained, 94 were found to have a prolonged $\mathrm{TpTe}$, while 61 had a prolonged TpTe/QT.

\section{BASELINE CHARACTERISTICS}

Of the 205 identified patients, $99.5 \%$ were male, $66.8 \%$ were Caucasian and the mean age was 66.6 $+/-12.3$ years (Table 1 ). The mean duration on dialysis prior to the first ECG being obtained was $104+/$ 11.7 days.

\section{Normal VS. PROLOnged TPTE}

Caucasians were more likely to have prolonged $\mathrm{TpTe}$ intervals $(66 / 137$ [48\%] normal vs. 71/137 [52\%] prolonged, $p=0.022$ ), whereas there was no statistically significant difference in numbers of African Americans with prolonged or normal $\mathrm{TpTe}$ or $\mathrm{TpTe} /$ QT intervals. There was no statistically significant difference in the proportion of patients with prolonged or normal TpTe with hypertension, congestive heart 
Figure 1. Pictorial representation illustrating how TpTe was calculated.

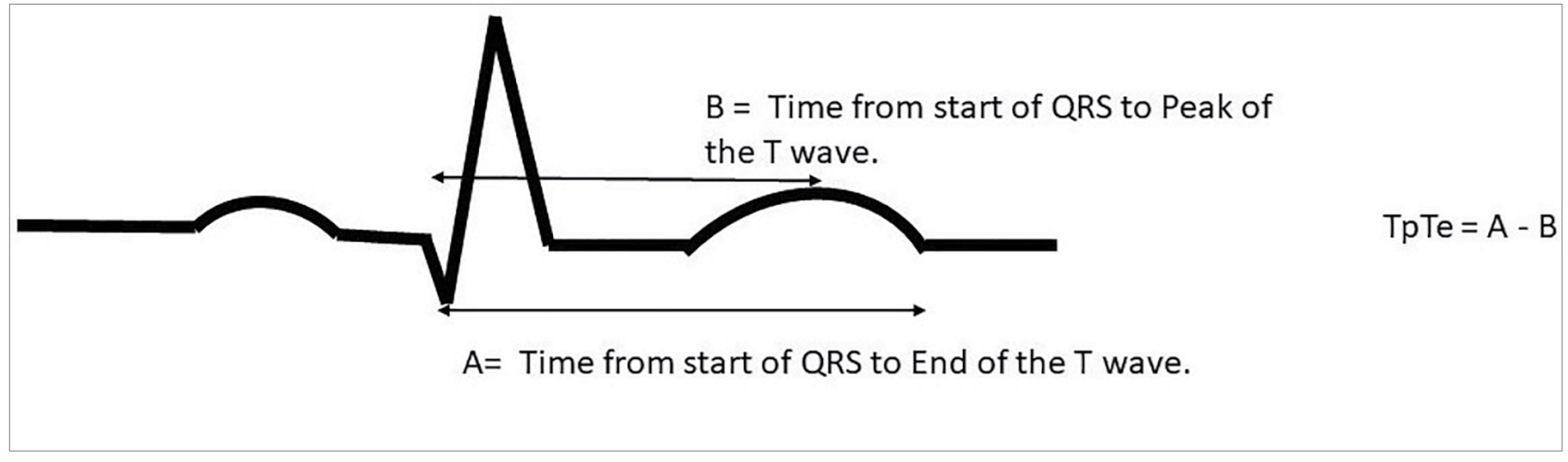

Figure 2. Patient selection.

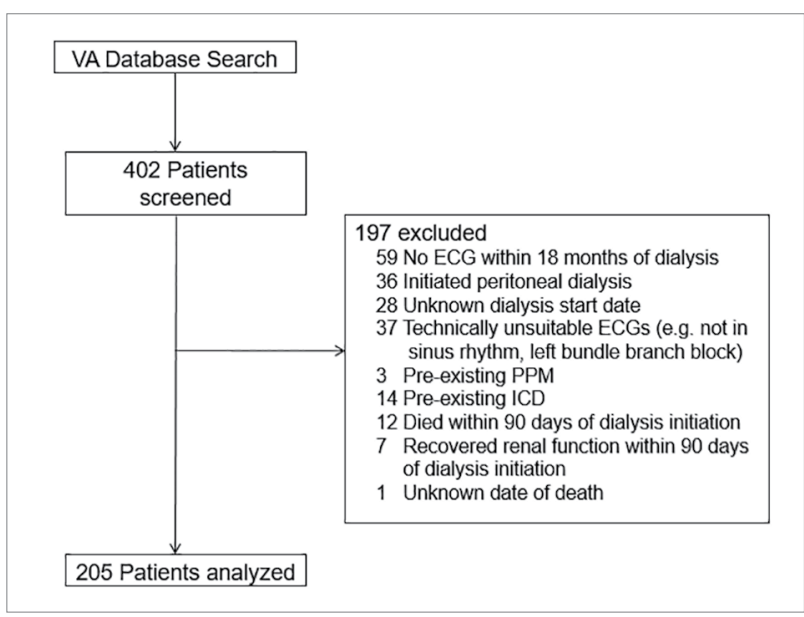

failure or other comorbidities (Table 1). The QRS duration was significantly longer in the prolonged $\mathrm{TpTe}$ group compared to normal TpTe $(98 \mathrm{~ms} v s .90 \mathrm{~ms}$, $p=0.01$ ). There was no statistical difference between normal or prolonged TpTe groups with regards to any other ECG parameter evaluated.

\section{NoRmal VS. PROLONGEDTPTE/QT}

There was no statistically significant difference between normal and prolonged $\mathrm{TpTe} / \mathrm{QT}$ patients in any demographic or co-morbid condition (Table 1). In contrast to the $\mathrm{TpTe}$ comparisons, there was no difference in racial category distribution between prolonged $\mathrm{TpTe} / \mathrm{QT}$ and normal TpTe/QT groups. The QRS duration was significantly longer in the prolonged TpTe/QT group (98 ms prolonged $v$ s. $92 \mathrm{~ms}$ normal, $p=0.046$ ) but no other ECG parameter was significantly different between the two groups.

\section{OUtCOMES - NORMAL VS. PROLONGEDTPTE}

Subjects were followed for a mean of 3.5 years. The mean survival times for patients with a normal and prolonged TpTe interval after dialysis initiation were 2.91 and 2.83 years, respectively (Figure $3 \mathrm{~A}$ ). No significant difference was observed in the rates of SCD or all-cause mortality between patients with a prolonged TpTe compared to a normal interval (Figures 3a and $3 \mathrm{~b})$. All-cause mortality in patients with a prolonged TpTe $v$ s. normal was $72.3 v$ s. $68.5 \%$ ( $p=0.76$ ). SCD in patients with prolonged TpTe $v s$. normal was 16.0 vs. $14.4 \%(p=0.52)$.

\section{OUTCOMES - NORMAL VS. PROLONGEDTPTE/OT}

The median survival time for patients with a normal and prolonged TpTe/QT interval was 2.94 and 2.67 years, respectively. Once again, there was no statistically significant difference seen in the rates of SCD or all-cause mortality between the normal and prolonged TpTe/QT groups. All-cause mortality was 68.8 vs. $70.8 \%$ in patients with prolonged compared to normal TpTe/QT ( $p=0.26$ ) (Figure 4A). SCD was present in 13.1 vs. $16 \%$ in patients with prolonged TpTe/QT compared to normal TpTe/QT ( $p=0.51)$ (Figure 4B).

\section{Cause of DEATH}

No statistical difference was found in cause of death between patients with normal and prolonged TpTe (Table 2). However, there was a trend of increased mortality from infection in patients with normal $\operatorname{TpTe}(p=0.09)$. No significant difference in cause of death was observed when comparing normal and prolonged TpTe/QT groups.

\section{Discussion}

In this analysis of 205 patients on maintenance hemodialysis therapy, the finding of a prolonged $\mathrm{TpTe}$ or prolonged $\mathrm{TpTe} / \mathrm{QT}$ at or near the time of initiating 


\begin{tabular}{|c|c|c|c|c|c|c|c|}
\hline & $\begin{array}{c}\text { All } \\
(n=205)\end{array}$ & $\begin{array}{l}\text { Normal } \\
\text { TpTe } \\
(\mathrm{n}=111)\end{array}$ & $\begin{array}{l}\text { Prolonged } \\
\text { TpTe } \\
(\mathrm{n}=94)\end{array}$ & $\begin{array}{c}\text { pvalue } \\
\text { (Normal } \\
\text { vs. } \\
\text { Prolonged } \\
\text { TpTe) }\end{array}$ & $\begin{array}{l}\text { Normal } \\
\text { TpTe/QT } \\
(\mathrm{n}=144)\end{array}$ & $\begin{array}{c}\text { Prolonged } \\
\text { TpTe/QT } \\
(\mathrm{n}=61)\end{array}$ & $\begin{array}{c}p \text { value } \\
\text { (Normal } \\
\text { vs. } \\
\text { Prolonged } \\
\text { TpTe/QT) }\end{array}$ \\
\hline Age, years & $66.6 \pm 12.3$ & $65.9 \pm 12.4$ & $67.3 \pm 12.2$ & 0.40 & $65.7+1.1$ & $67.5+1.5$ & 0.36 \\
\hline Gender, males (\%) & 99.5 & 100 & 98.9 & 0.93 & 100 & 98.4 & 0.66 \\
\hline Time to ECG, days & $104 \pm 11.7$ & $95 \pm 11.9$ & $115 \pm 11.4$ & 0.069 & $94+9.6$ & $128+15.3$ & 0.055 \\
\hline \multicolumn{8}{|l|}{ Race, n (\%) } \\
\hline White & $137(66.8)$ & 66 (59.5) & $71(75.5)$ & 0.022 & $93(64.6)$ & $44(72.1)$ & 0.58 \\
\hline African American & $61(29.8)$ & $41(36.9)$ & $20(21.3)$ & 0.18 & 45 (31.3) & $15(24.6)$ & 0.55 \\
\hline \multicolumn{8}{|l|}{ Cause of ESRD, n (\%) } \\
\hline Diabetic nephropathy & $94(45.9)$ & $51(45.9)$ & $43(45.7)$ & & $64(44.4)$ & $30(49.2)$ & \\
\hline Hypertension & $24(11.7)$ & $15(13.5)$ & $9(9.6)$ & & $18(12.5)$ & $6(9.8)$ & \\
\hline Glomerular disease & $22(10.7)$ & $11(9.9)$ & $11(11.7)$ & & $17(11.8)$ & $5(8.2)$ & \\
\hline Acute kidney injury & $15(7.3)$ & $10(9)$ & $5(5.3)$ & & $12(8.3)$ & $3(5)$ & \\
\hline Obstruction & $8(3.9)$ & $2(1.8)$ & $6(6.4)$ & & $4(2.8)$ & $4(4.9)$ & \\
\hline Ischemic nephropathy & $5(2.4)$ & $5(4.5)$ & $0(0)$ & & $5(3.5)$ & $0(0)$ & \\
\hline Polycystic kidney & $5(2.4)$ & $3(2.7)$ & $2(2.1)$ & & $3(2.1)$ & $2(3.3)$ & \\
\hline Unknown/Other & $32(15.6)$ & $14(12.6)$ & $18(19.2)$ & & $21(14.6)$ & $11(18)$ & \\
\hline \multicolumn{8}{|l|}{ ECG (mean, 95\% Cl) } \\
\hline PR interval & & $\begin{array}{c}170 \\
(152,194)\end{array}$ & $\begin{array}{c}168 \\
(151,194)\end{array}$ & 0.99 & $\begin{array}{c}172 \\
(152,194)\end{array}$ & $\begin{array}{c}166 \\
(148,194)\end{array}$ & 0.47 \\
\hline QRS duration, ms & & $\begin{array}{c}90 \\
(84,102)\end{array}$ & $\begin{array}{c}98 \\
(89.5,112)\end{array}$ & 0.01 & $\begin{array}{c}92 \\
(84,102)\end{array}$ & $98(90,114)$ & 0.05 \\
\hline $\begin{array}{l}\text { Left } \\
\text { ventricularhypertrophy, } \\
\mathrm{n}(\%)\end{array}$ & & $8(7.2)$ & $12(12.8)$ & 0.27 & $12(8.3)$ & $8(13.1)$ & 0.41 \\
\hline Fascicular Block & & $9(8.1)$ & $9(9.6)$ & 0.9 & $3(8.1)$ & $5(8.2)$ & 1 \\
\hline RBBB & & $12(10.8)$ & $13(13.8)$ & 0.66 & $3(8.1)$ & $5(8.2)$ & 1 \\
\hline QTc interval, ms & & $\begin{array}{c}451 \\
(426,470)\end{array}$ & $\begin{array}{c}453 \\
(434,476)\end{array}$ & 0.3 & $\begin{array}{c}447 \\
(426,473)\end{array}$ & $\begin{array}{c}457 \\
(434,475)\end{array}$ & 0.2 \\
\hline TpTe interval, ms & & $\begin{array}{c}71.3 \\
(56.3,80.5)\end{array}$ & $\begin{array}{c}103.5 \\
(93.8,120)\end{array}$ & $<0.001$ & $\mathrm{n} / \mathrm{a}$ & $\mathrm{n} / \mathrm{a}$ & \\
\hline TpTe/QTc interval, ms & & $\mathrm{n} / \mathrm{a}$ & $\mathrm{n} / \mathrm{a}$ & & $\begin{array}{c}0.18 \\
(0.15,0.21) \\
\end{array}$ & $\begin{array}{c}0.28 \\
(0.26,0.32) \\
\end{array}$ & $<0.001$ \\
\hline \multicolumn{8}{|l|}{ Comorbidities n (\%) } \\
\hline Hypertension & $182(88.8)$ & $97(87.4)$ & $85(90.4)$ & 0.64 & $128(88.9)$ & $54(88.5)$ & 0.87 \\
\hline Diabetes & $135(65.9)$ & $74(66.7)$ & $61(64.9)$ & 0.91 & $96(66.7)$ & 39 (63.9) & 0.83 \\
\hline CAD & $87(42.4)$ & $46(41.4)$ & $41(43.6)$ & 0.86 & $63(43.8)$ & 24 (39.3) & 0.67 \\
\hline $\mathrm{CHF}$ & $80(39.0)$ & 37 (33.3) & $43(45.7)$ & 0.09 & $54(37.5)$ & $26(42.6)$ & 0.6 \\
\hline BMI (Mean, 95\% Cl) & & $\begin{array}{c}27.4 \\
(24.8,32.3)\end{array}$ & $\begin{array}{c}28.9 \\
(24.3,32.3)\end{array}$ & 0.54 & $\begin{array}{c}28.2 \\
(25.1,32.3)\end{array}$ & $\begin{array}{c}28.4 \\
(23.9,32)\end{array}$ & 0.75 \\
\hline
\end{tabular}

BMI: body mass index; CAD: coronary artery disease; CHF: congestive heart failure; Cl: confidence interval; ECG: electrocardiogram; ESRD: end stage renal disease; PR: PR interval; QTc: corrected QT interval; RBBB: right bundle branch block; TpTe: T peak to T end interval; TpTe/QT: TpTe interval corrected for the QT interval. 
Figure 3. Overall survival (A) and survival without sudden cardiac death (B) between hemodialysis patients with normal and prolonged TpTe interval.

A

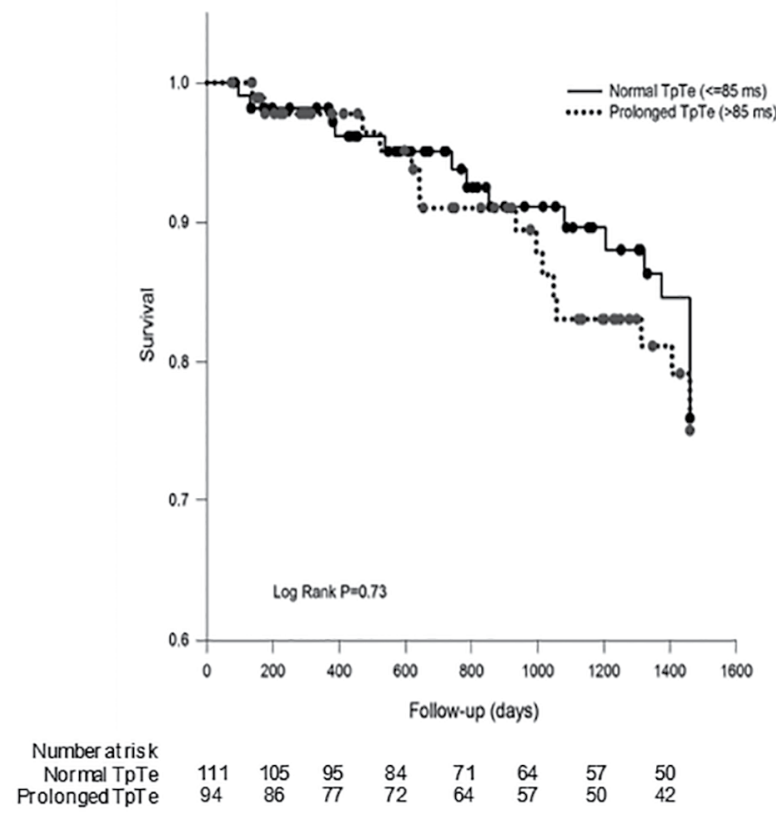

Number at risk

Normal TpTe

Prolonged TpTe
B

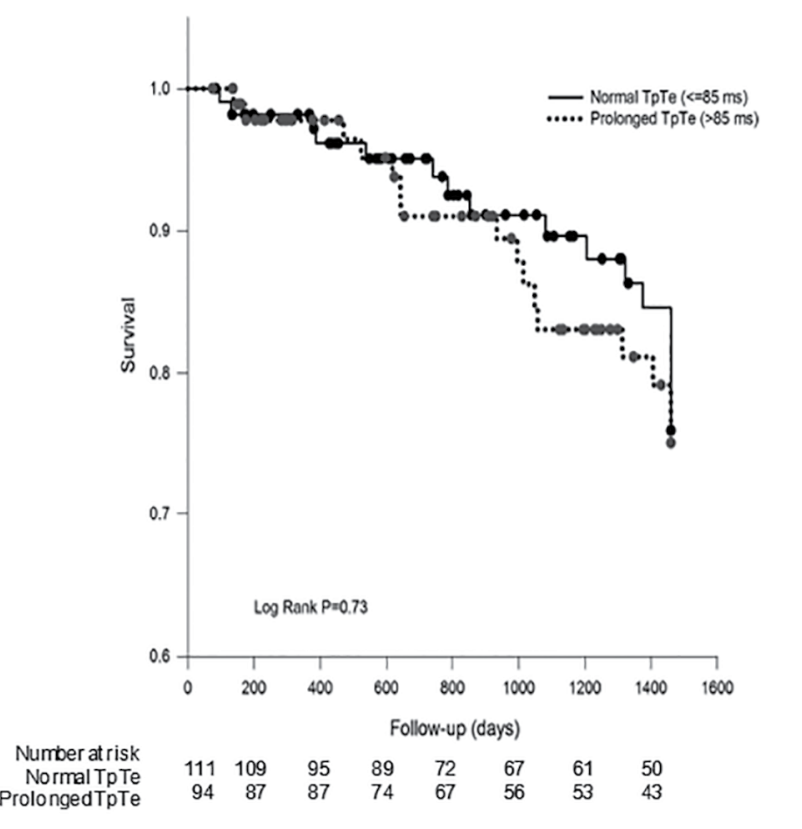

Figure 4. Overall survival $(\mathrm{A})$ and survival without sudden cardiac death $(\mathrm{B})$ between hemodialysis patients with normal and prolonged TpTe/QT interval.

A

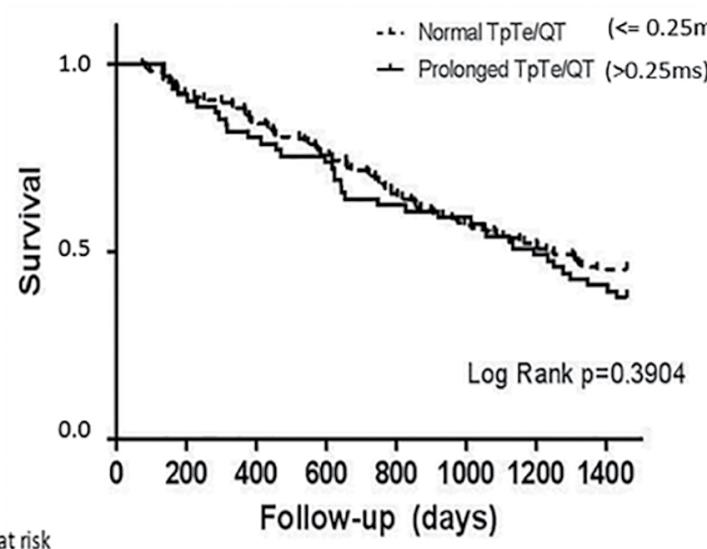

Number at risk

Normal TpTe/QT $144 \quad 133 \quad 122 \quad 109 \quad 94 \quad 83 \quad 75 \quad 66$

$\begin{array}{lllllllll}\text { Prolonged TpTe/QT } & 61 & 57 & 49 & 46 & 39 & 37 & 31 & 26\end{array}$
B

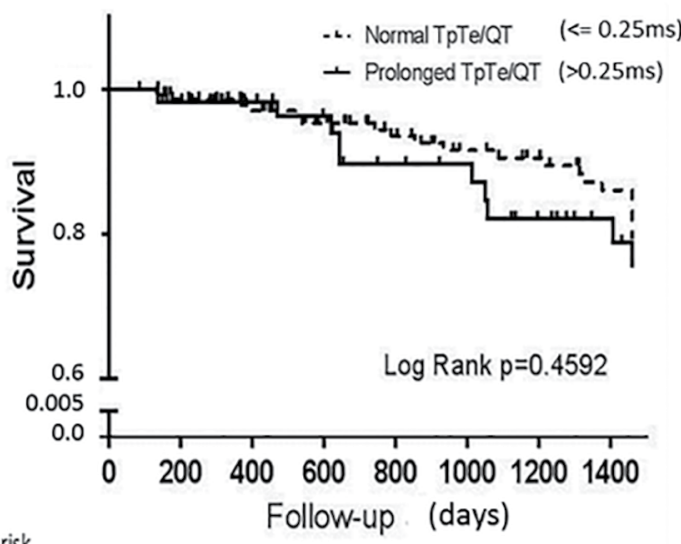

Number at risk

$\begin{array}{lllllllll}\text { Normal TpTe/QT } & 144 & 136 & 125 & 114 & 100 & 91 & 86 & 78\end{array}$

$\begin{array}{lllllllll}\text { Prolonged TpTe/QT } & 61 & 57 & 50 & 46 & 39 & 37 & 31 & 26\end{array}$

for cardiovascular $(\mathrm{CV})$ disease, which are ubiquitous among patients with ESRD, provide little predictive discrimination for those at higher risk of developing $\mathrm{CV}$ events, especially SCD. ${ }^{5-7}$ Traditional markers

It is well established that there is a high incidence of cardiovascular morbidity and mortality in the ESRD population. ${ }^{1,18}$ Unfortunately, traditional risk factors provide general assessments of vascular health and 


\begin{tabular}{|c|c|c|c|c|c|c|c|c|}
\hline TABLE 2 & USES OF DE & & & & & & & \\
\hline $\begin{array}{l}\text { Cause of } \\
\text { Death }\end{array}$ & $\begin{array}{c}\text { All } \\
(N=205)\end{array}$ & $\begin{array}{c}\text { Normal } \\
\text { TpTe } \\
(\mathrm{N}=111)\end{array}$ & $\begin{array}{l}\text { Prolonged } \\
\qquad \text { TpTe } \\
\text { (N = 94) }\end{array}$ & $\begin{array}{c}\text { p value } \\
\text { (Normal } \\
\text { vs. } \\
\text { Prolonged } \\
\text { TpTe) }\end{array}$ & $\begin{array}{c}\text { Normal } \\
\text { TpTe/QT } \\
(\mathrm{N}=144)\end{array}$ & $\begin{array}{l}\text { Prolonged } \\
\text { TpTe/QT } \\
(\mathrm{N}=61)\end{array}$ & $\begin{array}{c}p \text { value } \\
\text { (Normal } \\
\text { vs. } \\
\text { Prolonged } \\
\text { TpTe/QT) }\end{array}$ & $\begin{array}{c}\text { p value } \\
\text { (Prolonged } \\
\text { TpTe vs } \\
\text { Prolonged } \\
\text { TpTe/QT) }\end{array}$ \\
\hline SCD, n (\%) & $31(15.1)$ & $16(14.4)$ & $15(15.9)$ & 0.52 & $23(16)$ & $8(13.1)$ & 0.51 & 0.94 \\
\hline Infection, n (\%) & $22(10.7)$ & $14(12.6)$ & $8(8.5)$ & 0.09 & $18(12.5)$ & $4(6.5)$ & 0.88 & 0.87 \\
\hline $\begin{array}{l}\text { Non-SCD } \\
\text { cardiac, n (\%) }\end{array}$ & $17(8.2)$ & $10(9.0)$ & $7(7.4)$ & 0.28 & $12(8.3)$ & $5(8.1)$ & 0.82 & 0.65 \\
\hline Unknown, n (\%) & $18(8.7)$ & $11(9.9)$ & $7(7.4)$ & 0.19 & $12(8.3)$ & $6(9.8)$ & 0.54 & 0.42 \\
\hline Other, n (\%) & $56(27.3)$ & $25(22.5)$ & 31 (32.9) & 0.86 & 37 (25.6) & $19(31.1)$ & 0.13 & 0.70 \\
\hline $\begin{array}{l}\text { All-cause } \\
\text { Mortality, n (\%) }\end{array}$ & $144(70.2)$ & $76(68.5)$ & 68 (72.3) & 0.76 & $102(70.8)$ & $42(68.8)$ & 0.41 & 0.26 \\
\hline
\end{tabular}

may not be specific enough to influence adequate risk reduction measures in regard to SCD in patients with ESRD. The majority of SCD cases are presumed to be related to ventricular arrhythmias, although the possibility of PEA/asystole or bradycardic arrest is not ruled out in analyses focusing on baseline ECG parameters, as ours. Patients with ESRD, especially those on hemodialysis, are chronically exposed to homeostatic changes that could perturb the electrical conductance of the myocardium. Such changes should readily be evident in a resting ECG but investigating the predictive ability of ECG findings in ESRD patients is not novel. In a sub analysis of the German diabetic dialysis study (4D), 9 ECG parameters were examined for their ability to predict mortality in ESRD patients. ${ }^{19}$ The authors found that the only ECG parameter predictive of increased mortality was the absence of sinus rhythm, while signs of MI, heart rate, QRS axis, AV block, complete LBBB or RBBB, and QT interval had no significant association with outcomes. Several possibilities might explain these findings. First, structural defects are perhaps more important than conduction abnormalities in the genesis of SCD in ESRD. Second, uremia and the subsequent CV changes with the additional stress of the dialysis procedure are the primary determinants of SCD, and thus indifferent to the underlying electrical and structural defects of the heart. Third, routine ECG measurements are not specific enough to the high risk conduction abnormalities in the highly altered environment of ESRD. Our investigation sought to examine this last possibility. We examined the predictive ability of TpTe, an ECG marker of arrhythmogenesis that has been shown to be predictive of SCD in other populations.
It is important to first understand the basis for the TpTe measurement to understand its significance. The TpTe interval represents the speed of the dispersion of the repolarization potential from the epimyocardium to the endomyocardium. ${ }^{20,21} \mathrm{~A}$ delay in this interval allows the possibility of pre-excitation and induction of arrhythmia. ${ }^{22}$ This measure has been demonstrated to predict non-sustained ventricular tachycardia post-cardiac resynchronization and ICD firing in patients requiring the placement of $\mathrm{Bi}-\mathrm{V}$ pacing and ICD, as well as predict overall mortality and VT/VF in patients with systolic dysfunction and ICD implantation for primary prevention. ${ }^{23,24}$ While a difference in electric potentials (i.e. dispersion) between cell lines will always be present, increases in the dispersion have been linked to worse outcomes in disease states. ${ }^{14-16,25}$ One explanation as to why TpTe may be prolonged in ESRD patients is the presence of an increase in myocardial fibrosis in this population. Fibrosis can lead to heterogeneous zones of repolarization within the myocardium, which can induce ventricular arrhythmias. ${ }^{26}$

Our study failed to demonstrate a significant association between prolonged $\mathrm{TpTe}$ and outcomes in our ESRD study population, despite there being more events numerically (all-cause mortality and SCD) in the prolonged interval groups. Some studies showed improved precision in predicted SDC when TpTe is adjusted for heart rate. ${ }^{27}$ Another possible reason is that the dialysis treatment itself exerts a similar effect on cardiac function and conduction in all patients. In an analysis of the effects of dialysis on TpTe and TpTe/QT, Kalantzi et al. found that both intervals were increased in duration after a 
single hemodialysis session. ${ }^{17}$ Prolongation of TpTe or $\mathrm{TpTe} / \mathrm{QT}$ was not associated with changes in electrolytes, which suggest that the changes in $\mathrm{TpTe}$ were not related to the large electrolyte shifts that routinely occur in patients receiving hemodialysis. Other authors have examined the effect of hemodialysis on QT dispersion, which is another marker of the dispersion of ventricular repolarization. They also found that QT dispersion was increased after HD sessions. ${ }^{28}$ Additionally, other authors found that high frequency QRS duration was significantly increased after HD sessions, further bolstering the premise that dialysis itself alters ECG parameters. ${ }^{29}$ Nevertheless, such effects should, in theory, have more effect on those with pre-existent abnormalities in the conduction parameters. The question then becomes: are these changes consistent risk parameters over time? It is possible that uremic control over time with dialysis may change these parameters: some patients who started with a prolonged TpTe or TpTe/QT may have improvement over time, or all patients may develop a prolonged TpTe or prolonged TpTe/QT thereby eliminating any potential predictive ability over time. ECG changes over the course of time on hemodialysis or peritoneal dialysis may be more important in the evolving CV mortality related to ESRD. Thus, our study may not have been able to detect a significant effect on mortality without following the TpTe duration throughout many dialysis treatments. Perhaps, the amount by which TpTe changes over time, and not an absolute value, could more accurately predict mortality. Others have suggested that single markers like Tpte will not be effective as a predictive measure as a combination of many simultaneous ECG parameters. ${ }^{7,30}$

There was a higher proportion of African Americans within the normal TpTe group compared to prolonged TpTe group. Racial differences on standard ECG parameters have been previously shown. ${ }^{31}$ In fact, a recent study as part of the Women's Health Initiative found the upper limit of normal for $\mathrm{TpTe}$ to be 10 ms longer in African American women compared to Caucasian, Hispanic, and Asian women. ${ }^{32}$ While that study looked only at women, it seems to contradict our findings that African American men are more likely to have a shorter TpTe interval. Further investigations into the importance of ethnicity and gender on these ECG parameters are needed.
There are several limitations in this study. Due to the way we defined baseline ECG, we cannot rule out a direct effect of hemodialysis duration on TpTe; however, restriction of the population to those who had an ECG within 60 days of initiating dialysis demonstrated similar results with no significant difference in mortality or SCD at 5 years following initiation of hemodialysis (data not shown). We did not collect data on the reason for obtaining the ECG (i.e. routine check $v$ s. suspicion for an acute event, e.g. pre-operative clearance $v s$. myocardial infarction); this might have introduced a selection bias. We also were unable to obtain information on medication use at baseline, which is important as certain medications have been shown to affect the TpTe interval. Another limitation is that our observed SCD event rate was lower than what has been previously reported. The SCD rate in the normal TpTe group at 4 years was $14.4 \%$ compared to the $19 \%$ rate that was used in the $a$ priori power analysis and may have led to a loss of power. Another item worth mentioning is that almost $15 \%$ of the patients screened were excluded because they did not have an ECG within 18 months of dialysis initiation. Given that these patients are at high risk for adverse cardiac events and likely would benefit from a baseline ECG at dialysis initiation, this should be an area of focus for nephrologists and cardiologists. This also resulted in a relatively small population with limited follow-up time. Lastly, it should be noted that this study represents a Virginia (USA) population that is predominantly male and Caucasian, which limits the generalizability of these findings.

\section{Conclusion}

We hypothesized that in an ESRD population the presence of a prolonged TpTe or TpTe/QT segment would be predictive of increased all-cause mortality and/or SCD. Our study was unable to show a statistically significant difference in event rates between groups with prolonged and normal TpTe or TpTe/QT segments.

\section{ACKNOWLEDGEMENTS}

Support for VA/CMS data is provided by the Department of Veterans Affairs, Veterans Health Administration, Office of Research and Development, 
Health Services Research and Development, VA Information Resource Center (Project Numbers SDR 02-237 and 98-004).

This research did not receive any specific grant from funding agencies in the public, commercial, or not-for-profit sectors.

\section{References}

1. Collins AJ, Foley RN, Chavers B, Gilbertson D, Herzog C, Ishani A, et al. US Renal Data System 2013 Annual Data Report. Am J Kidney Dis 2014;63:A7.

2. Bernard SA, Gray TW, Buist MD, Jones BM, Silvester W, Gutteridge $\mathrm{G}$, et al. Treatment of comatose survivors of out-of-hospital cardiac arrest with induced hypothermia. N Engl J Med 2002;346:557-63

3. European Heart Rhythm Association; Heart Rhythm Society, Zipes DP, Camm AJ, Borggrefe M, Buxton AE, Chaitman B, Fromer M, et al.; American College of Cardiology; American Heart Association Task Force; European Society of Cardiology Committee for Practice Guidelines. ACC/AHA/ESC 2006 guidelines for management of patients with ventricular arrhythmias and the prevention of sudden cardiac death: a report of the American College of Cardiology/American Heart Association Task Force and the European Society of Cardiology Committee for Practice Guidelines (Writing Committee to Develop Guidelines for Management of Patients With Ventricular Arrhythmias and the Prevention of Sudden Cardiac Death). J Am Coll Cardiol 2006;48:e247-346.

4. Moss AJ, Zareba W, Hall WJ, Klein H, Wilber DJ, Cannom DS, et al.; Multicenter Automatic Defibrillator Implantation Trial II Investigators. Prophylactic implantation of a defibrillator in patients with myocardial infarction and reduced ejection fraction. N Engl J Med 2002;346:877-83.

5. Bleyer AJ, Hartman J, Brannon PC, Reeves-Daniel A, Satko SG, Russell G. Characteristics of sudden death in hemodialysis patients. Kidney Int 2006;69:2268-73.

6. Whitman IR, Feldman HI, Deo R. CKD and sudden cardiac death: epidemiology, mechanisms, and therapeutic approaches. J Am Soc Nephrol 2012;23:1929-39.

7. Waks JW, Tereshchenko LG, Parekh RS. Electrocardiographic predictors of mortality and sudden cardiac death in patients with end stage renal disease on hemodialysis. J Electrocardiol 2016;49:848-54.

8. Tracy CM, Epstein AE, Darbar D, DiMarco JP, Dunbar SB, Estes NA 3rd, et al.; American College of Cardiology Foundation; American Heart Association Task Force on Practice Guidelines; Heart Rhythm Society. 2012 ACCF/AHA/HRS focused update of the 2008 guidelines for device-based therapy of cardiac rhythm abnormalities: a report of the American College of Cardiology Foundation/American Heart Association Task Force on Practice Guidelines and the Heart Rhythm Society. [corrected]. Circulation 2012;126:1784-800.

9. Pun PH, Lehrich RW, Honeycutt EF, Herzog CA, Middleton JP. Modifiable risk factors associated with sudden cardiac arrest within hemodialysis clinics. Kidney Int 2011;79:218-27.

10. Deo R, Shou H, Soliman EZ, Yang W, Arkin JM, Zhang X, et al. Electrocardiographic Measures and Prediction of Cardiovascular and Noncardiovascular Death in CKD. J Am Soc Nephrol 2016;27:559-69.

11. Tereshchenko LG, Kim ED, Oehler A, Meoni LA, Ghafoori E, Rami T, et al. Electrophysiologic Substrate and Risk of Mortality in Incident Hemodialysis. J Am Soc Nephrol 2016;27:3413-20.

12. Guney M, Ozkok A, Caliskan Y, Pusuroglu H, Yazici H, Tepe $\mathrm{S}$, et al. QT dispersion predicts mortality and correlates with both coronary artery calcification and atherosclerosis in hemodialysis patients. Int Urol Nephrol 2014;46:599-605.
13. Antzelevitch C. Role of spatial dispersion of repolarization in inherited and acquired sudden cardiac death syndromes. Am J Physiol Heart Circ Physiol 2007;293:H2024-38.

14. Panikkath R, Reinier K, Uy-Evanado A, Teodorescu C, Hattenhauer J, Mariani R, et al. Prolonged Tpeak-to-tend interval on the resting ECG is associated with increased risk of sudden cardiac death. Circ Arrhythm Electrophysiol 2011;4:441-7.

15. Shimizu $M$, Ino $H$, Okeie $K$, Yamaguchi $M$, Nagata $M$, Hayashi $\mathrm{K}$, et al. T-peak to T-end interval may be a better predictor of high-risk patients with hypertrophic cardiomyopathy associated with a cardiac troponin I mutation than QT dispersion. Clin Cardiol 2002;25:335-9.

16. Haarmark C, Hansen PR, Vedel-Larsen E, Pedersen SH, Graff $\mathrm{C}$, Andersen MP, et al. The prognostic value of the Tpeak-Tend interval in patients undergoing primary percutaneous coronary intervention for ST-segment elevation myocardial infarction. J Electrocardiol 2009;42:555-60.

17. Kalantzi K, Gouva C, Letsas KP, Vlachopanou A, Foulidis V, Bechlioulis A, et al. The impact of hemodialysis on the dispersion of ventricular repolarization. Pacing Clin Electrophysiol 2013;36:322-7.

18. Saran R, Li Y, Robinson B, Ayanian J, Balkrishnan R, Bragg-Gresham J, et al. US Renal Data System 2014 Annual Data Report: Epidemiology of Kidney Disease in the United States. Am J Kidney Dis 2015;66:Svii, S1-305. Erratum in: Am J Kidney Dis 2015;66:545.

19. Krane V, Heinrich F, Meesmann M, Olschewski M, Lilienthal J, Angermann C, et al.; German Diabetes and Dialysis Study Investigators. Electrocardiography and outcome in patients with diabetes mellitus on maintenance hemodialysis. Clin J Am Soc Nephrol 2009;4:394-400.

20. Antzelevitch C, Sicouri S, Di Diego JM, Burashnikov A, Viskin S, Shimizu W, et al. Does Tpeak-Tend provide an index of transmural dispersion of repolarization? Heart Rhythm 2007;4:1114-6; author reply 1116-9.

21. Antzelevitch C, Yan GX, Shimizu W. Transmural dispersion of repolarization and arrhythmogenicity: the Brugada syndrome versus the long QT syndrome. J Electrocardiol 1999;32:15865.

22. Akar FG, Yan GX, Antzelevitch C, Rosenbaum DS. Unique topographical distribution of $\mathrm{M}$ cells underlies reentrant mechanism of torsade de pointes in the long-QT syndrome. Circulation 2002;105:1247-53.

23. Barbhaiya C, Po JR, Hanon S, Schweitzer P. Tpeak - Tend and Tpeak - Tend /QT ratio as markers of ventricular arrhythmia risk in cardiac resynchronization therapy patients. Pacing Clin Electrophysiol 2013;36:103-8.

24. Rosenthal TM, Stahls PF 3rd, Abi Samra FM, Bernard ML, Khatib S, Polin GM, et al. T-peak to T-end interval for prediction of ventricular tachyarrhythmia and mortality in a primary prevention population with systolic cardiomyopathy. Heart Rhythm 2015;12:1789-97.

25. Topilski I, Rogowski O, Rosso R, Justo D, Copperman Y, Glikson M, et al. The morphology of the QT interval predicts torsade de pointes during acquired bradyarrhythmias. J Am Coll Cardiol 2007;49:320-8.

26. Roes SD, Borleffs CJ, van der Geest RJ, Westenberg JJ, Marsan NA, Kaandorp TA, et al. Infarct tissue heterogeneity assessed with contrast-enhanced MRI predicts spontaneous ventricular arrhythmia in patients with ischemic cardiomyopathy and implantable cardioverter-defibrillator. Circ Cardiovasc Imaging 2009;2:183-90.

27. Chua KC, Rusinaru C, Reinier K, Uy-Evanado A, Chugh H, Gunson K, et al. Tpeak-to-Tend interval corrected for heart rate: A more precise measure of increased sudden death risk? Heart Rhythm 2016;13:2181-5.

28. Morris ST, Galiatsou E, Stewart GA, Rodger RS, Jardine AG. QT dispersion before and after hemodialysis. J Am Soc Nephrol 1999;10:160-3. 
29. Morales MA, Gremigni C, Dattolo P, Piacenti M, Cerrai T, Fazi A, et al. Signal-averaged ECG abnormalities in haemodialysis patients. Role of dialysis. Nephrol Dial Transplant 1998;13:668-73.

30. Abdelghani SA, Rosenthal TM, Morin DP. Surface Electrocardiogram Predictors of Sudden Cardiac Arrest. Ochsner J 2016;16:280-9.
31. Macfarlane PW, Katibi IA, Hamde ST, Singh D, Clark E, Devine $\mathrm{B}$, et al. Racial differences in the ECG--selected aspects. J Electrocardiol 2014;47:809-14.

32. Rautaharju PM, Zhang ZM, Gregg RE, Haisty WK Jr, Z Vitolins $\mathrm{M}$, Curtis $\mathrm{AB}$, et al. Normal standards for computer-ECG programs for prognostically and diagnostically important ECG variables derived from a large ethnically diverse female cohort: the Women's Health Initiative (WHI). J Electrocardiol 2013;46:707-16. 


\section{Erratum I Errata}

In the article "TpTe and TpTe/QT: novel markers to predict sudden cardiac death in ESRD?", with DOI code number 10.1590/2175-8239-jbn-2017-0021, published at Brazilian Journal of Nephrology, 41(1): 38-47, on the page 38:

Where it was written:

\section{Abstract}

Introduction: Reliable markers to predict sudden cardiac death (SCD) in patients with end stage renal disease (ESRD) remain elusive, but echocardiogram (ECG) parameters may help stratify patients.

\section{Resumo}

Introdução: Marcadores confiáveis para predizer morte súbita cardíaca (MSC) em pacientes com doença renal terminal (DRT) permanecem elusivos, mas os parâmetros do ecocardiograma (ECG) podem ajudar a estratificar os pacientes.

Should read:

\section{Abstract}

Introduction: Reliable markers to predict sudden cardiac death (SCD) in patients with end stage renal disease (ESRD) remain elusive, but electrocardiogram (ECG) parameters may help stratify patients.

\section{Resumo}

Introdução: Marcadores confiáveis para predizer morte súbita cardíaca (MSC) em pacientes com doença renal terminal (DRT) permanecem elusivos, mas os parâmetros do eletrocardiograma (ECG) podem ajudar a estratificar os pacientes. 